\title{
Documenting, analysing and managing the animal biodiversity in the Middle East - a challenge for the future
}

\author{
Eike Neubert \\ Naturhistorisches Museum der Burgergemeinde Bern, Bern, Switzerland \\ Corresponding author: Eike Neubert (eike.neubert@nmbe.ch) \\ Received 14 December 2009 | Accepted 14 December 2009 | Published 28 December 2009 \\ Citation: Neubert E (2009) Documenting, analysing and managing the animal biodiversity in the Middle East - a chal- \\ lenge for the future In: Neubert E, Amr Z, Taiti S, Gümüs B (Eds) Animal Biodiversity in the Middle East. Proceedings \\ of the First Middle Eastern Biodiversity Congress, Aqaba, Jordan, 20-23 October 2008. ZooKeys 31: 1-2. doi: 10.3897/ \\ zookeys. 31.370
}

It is with great pleasure that I present this special issue of ZooKeys: the Proceedings of the First International Congress on "Documenting, Analysing and Managing Biodiversity in the Middle East", which was held on October $20^{\text {th }}-23^{\text {rd }}, 2008$ in Aqaba, Jordan. This conference was a great success, and the Organising Committee received an overwhelmingly positive response from the participants, with many of them asking about the date of the next congress. The variety of subjects addressed in scientific talks, poster sessions, workshops and round-table discussions was amazingly broad and reflected the outstanding wealth of the Middle East in both, biota and habitats. A tremendous need of free communication, exchange of expertise, knowledge, biological specimens, etc. became obvious. Right from the onset, the First Middle Eastern Biodiversity Congress and the Proceedings were conceived as a communication platform.

The Proceedings presented here mirror the variety of biodiversity-related subjects being studied throughout the Middle East. In the field of zoology, they range from basic invertebrates like marine flatworms to various groups of vertebrates. All articles published in this volume attest the great amount of work still needed to produce an authoritative documentation of the biodiversity of the area, and it is our serious hope that the Congress and its Proceedings will stimulate and intensify future efforts at documenting this unique environment and its floral and faunal inhabitants.

Copyright E. Neubert. This is an open access article distributed under the terms of the Creative Commons Attribution License, which permits unrestricted use, distribution, and reproduction in any medium, provided the original author and source are credited. 


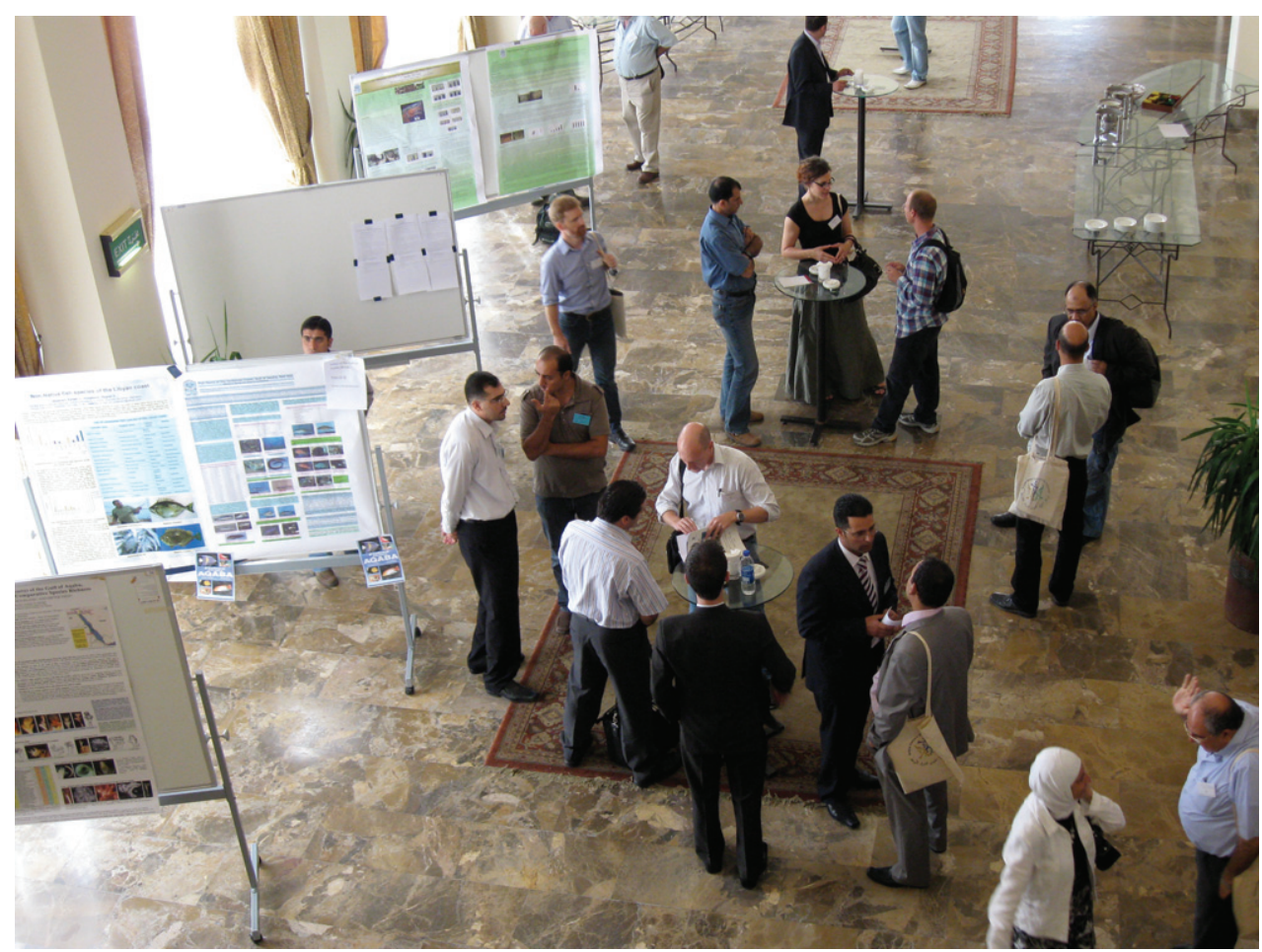

View on the lobby at the congress, InterConti Hotel Aqaba, October 2008 (phot.: R. Bonifer).

Not all articles submitted were accepted for publication in the Proceedings, and it was sometimes a difficult process to fair-mindedly assess their quality and coverage. I herewith express my gratitude to the colleagues, who as unpaid co-editors shared their skills and precious time with me, revising manuscripts and offering their professional expertise, thus guaranteeing high quality standards of this volume. These are my co-editors (in alphabetic order): Prof. Dr. Zuhair AmR (Jordan), Dr. Burçin Askim GüMüş (Turkey), and Dr. Stefano Taiti (Italy). Professor Dr. Ruud Bank (The Netherlands) and Dr. Fareed Krupp (Germany) are also acknowledged for their support. We would not have been able to realise this publication project without the enthusiasm of Dr. Lyubomir Penev and his professional team at Pensoft Publishers, particularly Ivailo STOYANOv.

Dr. Eike Neubert

Berne/Frankfurt, October 2009

(Editor-in-chief) 